\title{
Where to draw the lifeline?
}

\author{
Nayanah Siva
}

Once again, the UK's National Institute for Health and Clinical Excellence (NICE) is in the firing line. Since the body's negative appraisal of the drugs bevacizumab, sorafenib tosylate, sunitinib, and temsirolimus for renal cell carcinoma in August of this year infuriated patients, clinicians, charities, and drug companies themselves have protested against the provisional decision. Clinical studies have shown that the new drugs are clinically effective, with an estimated progression-free survival of 6-12 months. NICE have acknowledged that the drugs are clinically effective; however, at an estimated cost of between $£ 70,000$ and $£ 170,000$ per quality-adjusted life year per patient, the body have deemed the drugs not cost-effective.

Since its formation 9 years ago, NICE has come up against bitter criticism about their decisions on expensive medical treatments that at times have been approved in other countries. But why are media attention and patient protests so often targeted at NICE, and not at the pharmaceutical companies, for pricing drugs so highly?

Drug pricing is a complex issue. Manufacturing drugs is an expensive business and requires a substantial amount of resources and time, and pharmaceutical companies should, therefore, be appropriately compensated. Developing an entirely new drug can take as long as 12 years, with an average cost of $£ 550$ million - a substantial amount of which is used for funding unsuccessful drug trials. The UK government sets a maximum level of profit that drug companies can earn, any excess of which must be paid to the Department of Health, but, other than this, current regulations allow pharmaceutical companies the liberty to price individual drugs as they see fit. Despite this freedom, pharmaceutical companies have an uncertain future: in addition to the current turbulent financial climate, many of the big-branded drugs of the 1990s are soon
For each

patient, any

amount of

time, whether

months or

years, is

priceless,

but the NHS'

resources are

limited, and

sacrifices have

to be made

somewhere

N Siva is Locum

Editor of Nature

Clinical Practice

Urology.

Competing interests

The author declared no

competing interests.

www.nature.com/clinicalpractice doi:10.1038/ncpuro1258 to come off-patent, thereby limiting companies' future profits. Does this upcoming uncertainty mean that drug companies may be guilty of pricing new branded drugs to compensate for this potential loss of profit?

The UK's National Health Service (NHS) spends about $£ 11$ billion per year on prescription medicines, and it is struggling to pay for NICE-approved drugs as it is. A 2007 report from the UK Office of Fair Trading raised concerns about the NHS footing unnecessarily high drug bills, and they proposed that UK drug pricing regulations should be linked to therapeutic value; that is, drugs that deliver significant health benefits should be priced higher than drugs that only have minimal benefits to a limited number of patients. This system could potentially avoid unnecessary expenditure of millions of pounds by the NHS, and would follow the similar, successful drug pricing systems used in Canada and Norway.

Drug rationing for a nation is no easy task. And as Michael Rawlins, chairman of NICE, has commented, "the NHS is not a bottomless pit". The current method used by NICE to assess the clinical effectiveness versus costeffectiveness of a drug may not be ideal, but how else can such difficult decisions about drug rationing be made? For each patient, any amount of extra time, whether months or years, is priceless, but the NHS' resources are limited, and sacrifices have to be made somewhere. Should a patient with advanced renal cell carcinoma be allowed the chance of an extra couple of months to live, or should the patient with prostate cancer have the opportunity of treated disease-free survival? Importantly, such ugly decisions have been taken away from clinicians, who have their own conflicts of interest; that is, to treat the patient in front of them at whatever cost. The onerous task of drug allocation has to be done, and a regulatory body, such as NICE, is essential to consider how best to allocate limited resources. 